\title{
Neuroblastoma in an adult: Case report
}

\author{
PRISCILA BERNARDINA MIRANDA SOARES ${ }^{1,2}$, SIDNEI QUIRINO FILHO ${ }^{2}$, \\ WILLIAM PEREIRA DE SOUZA ${ }^{2}$, PAULO ROGÉRIO FERRETI BONAN ${ }^{1,2}$, \\ HERCÍLIO MARTELLI-JÚNIOR ${ }^{1,2}$
}

\begin{abstract}
Neuroblastoma is the most common extracranial solid malignancy in children but rarely described in adults, being 10\% of all cases diagnosed after the first decade of life. We report a 23 year-old black woman with a mass at paravertebral region of T3-T5, multiple lesions in vertebral bodies and expanding skull-brain lesion at the right parietal region. Immunohistochemical analysis (negative for CD99, CD20, CD3 and desmin; and positive chromogranin, synaptophysin and NB84) confirmed the diagnosis of neuroblastoma. The patient was submitted to 12 cycles of chemotherapy receiving VAC (vincristine/doxorubicin/cyclophosphamide) interspersed with ICE (ifosfamide/mesna/etoposide) and doxorubicin was replaced by actinomycin in the 7 th cycle. She had good tolerance to this therapy, and has been clinically stable.

(Rev Med Chile 2010; 138: 1131-1134).

Key words: Antineoplastic protocols; Drug Therapy; Neoplasms; Neuroblastoma.

Neuroblastoma en un adulto. Informe de un caso

El neuroblastoma es el tumor maligno sólido extracraneal más común en niños. Sólo el 10\% de los casos se diagnostican después de la primera década de vida. Presentamos una paciente afroamericana de 23 años, con una masa paravertebral en T3-T5, múltiples lesiones en los cuerpos vertebrales y una lesión expansiva en la región parietal derecha. El estudio inmmunohistoquímico (negativo para CD99, CD20, CD3 y desmina y positivo para cromogranina, sinaptofisina y NB84), confirmó el diagnóstico de neuroblastoma. La paciente fue sometida a 12 ciclos de quimioterapia recibiendo VAC (vincristina / doxorubicina/ cyclofosfamida) intercalada con ICE (ifosfamida/ mesna/ etoposido). La doxorubicina fue reemplazada por actinomicina en el séptimo ciclo. La paciente toleró bien la quimioterapia y está clínicamente estable.
\end{abstract}

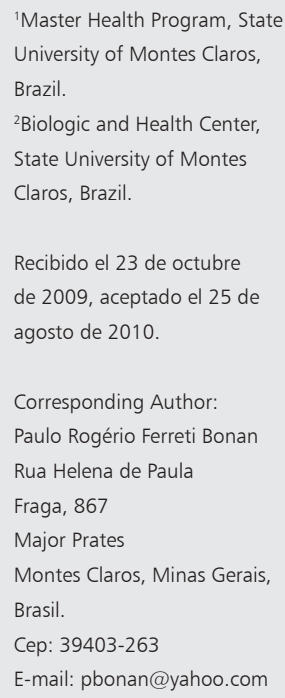

$\mathrm{N}$ euroblastoma is a malignant neoplasm derived from neural crest cells, located preferentially at the medullary region of the adrenal gland, less frequently found at other sites $^{1}$. Neuroblastoma is the most common extracranial solid malignancy in children, representing $7.7 \%$ of all pediatric cancers, with an incidence of 2.26 cases per million/year ${ }^{1,2}$. It is rarely described in adults, being $10 \%$ of all cases diagnosed after the first decade of life 3 .

In adults, neuroblastoma has distinctive bio-

logical and clinical features as compared with the pediatric population. However, in both groups, the prognosis of the tumor is greatly influenced by the duration of diagnostic delay ${ }^{4}$. There is no standard treatment protocol for neuroblastoma in adults. However, adults have a lower tolerance to the treatment when compared with children ${ }^{6}$. Even with intensive chemotherapy, the majority of adult patients present multiple recurrences and refractoriness to treatment ${ }^{6}$. Considering the rarity of the occurrence of neuroblastoma in adults, the 
aim of this study is to present a case report of this malignant neoplasm with skull-brain metastasis and spinal cord compression syndrome.

\section{Case report}

A 23 year-old black woman, born in the town of Bocaiúva, in the north of the State of Minas Gerais/Brazil, reported that in mid-2007, during her pregnancy, she had pain in the sacral region, which persisted after the delivery. She sought medical care, and then she was referred for physiotherapy, but without achieving clinical improvement. In December 2008, she manifested progressive paraparesis and numbness of lower limbs. Four months later, there was a marked worsening of thoracic and lumbar pain, with urinary tract infection and fever. Then, she was admitted to the Santa Casa Hospital in the town of Montes Claros, Minas Gerais. After clinical examination, additional laboratory tests were requested. The blood cell count revealed mild anemia, a level of serum lactate dehydrogenase of 990 IU/L and the other biochemical readings were normal. Thoracic spine MRI was performed identifying a mass at paravertebral region of T3-T5, with extension into the spinal canal (epidural), with multiple lesions in vertebral bodies (Figure 1). Local surgical decompression, biopsy of the paravertebral mass, and radiotherapic decompression were carried out as a matter of urgency. During diagnostic workup while waiting for the results of histopathological diagnosis, the patient developed acute headache, and the CT scan identified an expanding skullbrain lesion at the right parietal region (Figure 1). Palliative cranial radiation therapy was given. The biopsied material was processed in $\mathrm{HE}$, and histopathological diagnosis was consistent with undifferentiated malignant neoplasm. Immunohistochemical analysis (negative for CD99, CD20, CD3 and desmin; and positive chromogranin, synaptophysin and NB84) confirmed the diagnosis of neuroblastoma (Figure 2). The scans of the abdomen and pelvis revealed lymphadenomegaly and internal and external iliac chains, with retrovesical and sacro-coccygeal mass, without involvement of the adrenal. After completion of histopathological diagnosis and before chemotherapy, VMA level was measured presenting normal reading.

The disease was spread at the diagnosis, with

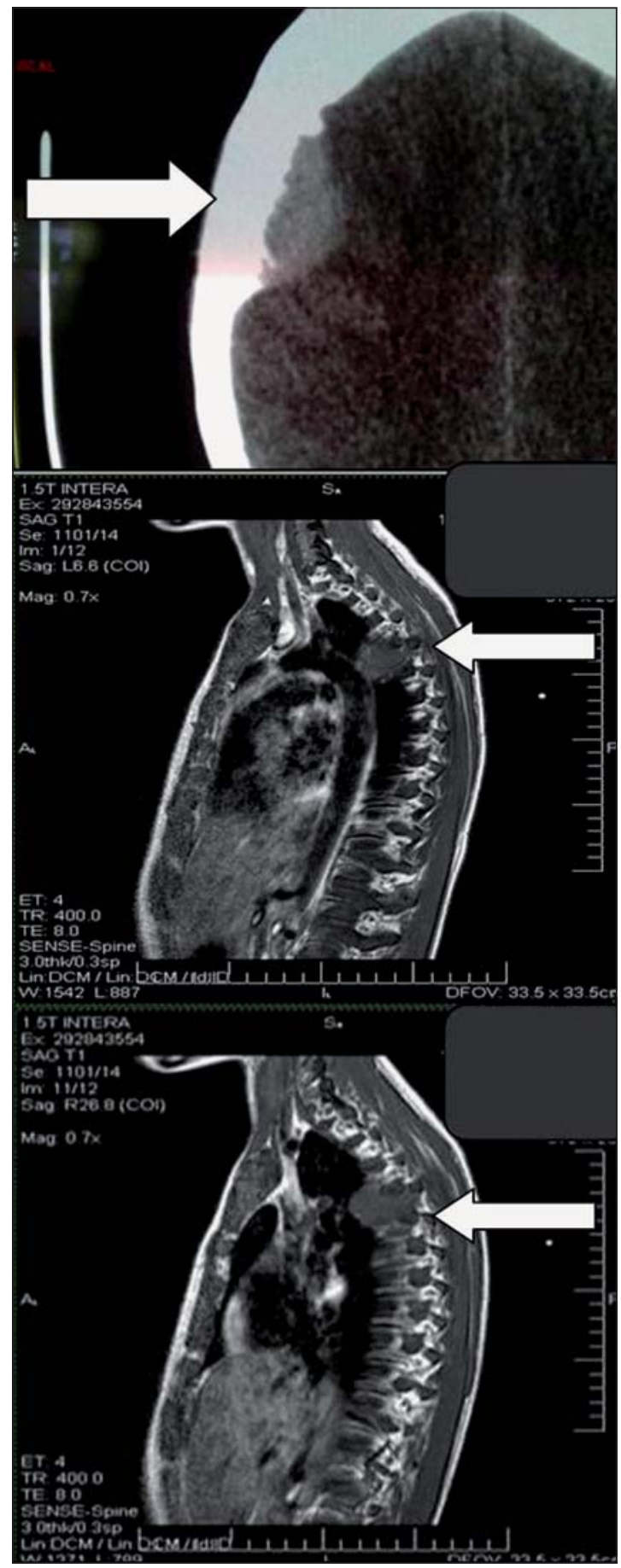

Figure 1. (Above) CT scan (axial view) identified an expanding skull-brain lesion at the right parietal region. (Medium and Below) RMI (T1 Sag Spair) revealed a solid lesion at paravertebral region of T3-T5, with extension into the spinal canal (epidural). 


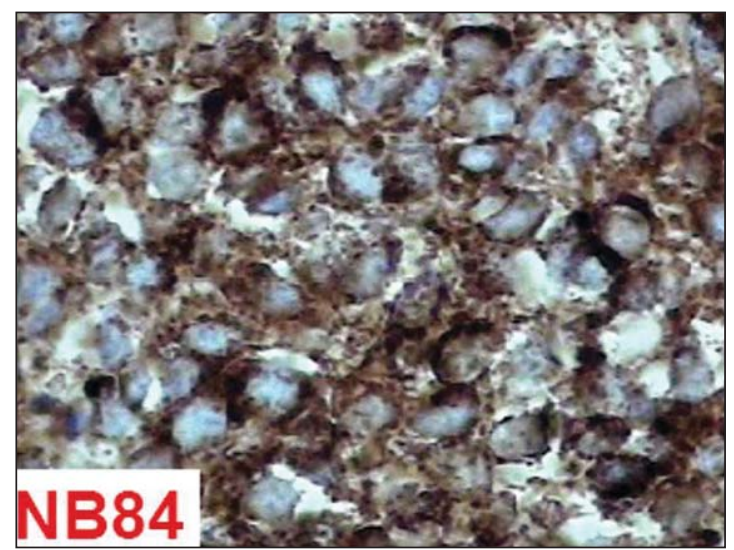

Figure 2. Immunohistochemical analysis showed positiveness to NB84 confirming the diagnosis of neuroblastoma (DAB). CD99 was negative, ruling out the possibility of Ewing's sarco$\mathrm{ma}$ / PNET - the main differential diagnosis of neuroblastoma. Negativeness to CD 20, CD 3 and desmin also ruled out the diagnosis of lymphoma and rhabdomyosarcoma.

skull-brain metastasis, spinal cord compression, multiple bone metastases (confirmed by bone scintigraphy), and infiltration of bone marrow (identified by biopsy of iliac crest).

The patient was submitted to 12 cycles of chemotherapy, the last one on March 2010. She received VAC (vincristine/doxorubicin/cyclophosphamide) interspersed with ICE (ifosfamide/ mesna/etoposide); doxorubicin was replaced by actinomycin in the 7th cycle (due to maximal accepted cumulative dose of doxorubicin reached). She had good tolerance to this therapy, and has been clinically stable. Radiologic examinations to evaluate treatment response after are in progress.

\section{Discussion}

Neuroblastoma shows an incidence of 2.26 cases per million inhabitants/year 2 ; $60 \%$ of the cases are diagnosed within the first 2 years of age, and $75 \%$ within the first 5 years of age. Case reports of this neoplasm over 18 years of age are rare, and this disease shows no preference for gender ${ }^{1}$. The clinical features of neuroblastoma in adults are similar in children. The exception is that the bone marrow involvement occurs less frequently in adults, and there is a higher frequency of metastases at unusual sites such as lung or brain ${ }^{5}$.
The primary tumor site basically reflects the distribution of the sympathetic nervous system. This distribution is similar among adults and children $^{1,2}$. This case study reported the occurrence of neuroblastoma in an adult with disseminated disease at diagnosis, skull-brain metastasis, spinal cord compression, multiple bone metastases, and bone marrow infiltration.

There is no consensus regarding the treatment of neuroblastoma in adults. It seems that, in some studies, the treatment is similar to the protocol in children. Treatment options include surgical resection, chemotherapy or radiotherapy ${ }^{6-8}$. There are limitations in the longitudinal studies focusing on adult's neuroblastoma treatment due to the rare reports of this neoplasm in adults. The most active therapeutic agents used alone or in combination include cyclophosphamide, cisplatin, doxorubicin, carboplatin and ifosfamide. In general, neuroblastoma in adults has a protracted pre-symptomatic course, with a longer delay between symptom onset and diagnosis, although it seems there is no difference in prognosis between adults and children diagnosed at the same stage of the disease $e^{1,2}$. Regarding prognosis and survival, there was a continuous reduction in survival in a 10-year follow-up. Patients with localized disease or regionally advanced showed better survival than those with advanced metastatic disease. However, there is a trend of improvement in the results when considering the figures from 1970-1990's: in 1970's the relative survival at 5 years was $28 \%$, rising to 38 and $49 \%$ in the 1980's and 1990's, respectively'.

With regards to histological diagnosis, it is known that undifferentiated neoplasm is a generic term for a group of highly aggressive malignant tumors composed by undifferentiated small round and blue cells and with a high nucleus-cytoplasm ratio. Due to this fact, neuroblastoma presents common morphological characteristics with Ewing sarcoma / PNET, rhabdomyosarcoma, and lymphoma, requiring immunomarkers to distinguish one of others. Immunohistochemistry was performed in this case showing expression of chromogranin, synaptophysin and especially NB84 supporting the diagnosis of neuroblastoma. Negativeness to CD99, CD20 and 3 and Desmin ruled out the possibility of treating respectively Ewing's sarcoma/Pnet, lymphoma and Rabdomiossarcoma ${ }^{10}$.

In summary, this case report illustrates neuroblastoma as an extremely rare neoplasm in 
adults. There are clinical and biological features of this tumor in adults that may explain the clinical course and poor response to treatments. It was also observed that the diagnosis in adults presents a worse outcome than that in children. However, there is a trend of improvement in survival in recent decades, what may reflect advances in treatments. Future research focusing on tumor biology and treatment of this rare tumor in adults may contribute toward the improvement of final results.

\section{References}

1. Kaye JA, Warhol MJ, Kretschmar C, Landsberg L, Frei E. Neuroblastoma in adults. Three cases reports and review of the literature. Cancer 1986; 58: 1149-57.

2. Davis S, Rogers MA, Pendergrass TW. The incidence and epidemiology characteristics of neuroblastomas in the United States American. J Epidemiol 1987; 126: 1063-74.

3. Castleberry RP. Biology and treatment of neuroblastoma. Pediatr Clin North Am 1997; 44: 919-37.

4. Attiyeh EF, London WB, Mossé YP, Wang Q, Winter C, Khazi $\mathrm{D}$ et al. Chromosome $1 \mathrm{p}$ and $11 \mathrm{q}$ deletions and outcome in neuroblastoma. N Engl J Med 2005; 353: 2243-53.

5. Conte M, Parodi S, De Bernardi B, Milanaccio C, Mazzocco K, Angelini P, et al. Neuroblastoma in adolescents: the Italian experience. Cancer 2006; 106: 1409-17.

6. Franks LM, Bollen A, Seeger RC, Stram DO, Matthay KK. Neuroblastoma in adults and adolescents: an indolent course with poor survival. Cancer 1997; 79: 202835.

7. Kushner BH, Kramer K, LaQuaglia MP, Modak S, Cheung NK. Neuroblastoma in adolescents and adults: The Memorial Sloan-Kettering experience. Med Pediatr Oncol 2003; 41: 508-15.

8. Simon T, Langler A, Berthold F, Klingebiel T, Hero B. Topotecan and etoposide in the treatment of relapsed high-risk neuroblastoma: results of phase 2 trial. J Pediatr Hematol Oncol 2007; 29: 101-6.

9. Esiashvili N, Goodman M, Ward K, Marcus RB Jr, Johnstone PA. Neuroblastoma in adults: incidence and survival analysis based on SEER data. Pediatr Blood Cancer 2007; 49: 41-6.

10. Miettinen M, Chalten J, Paetau A, Stevenson A. Monoclonal antibody NB84 in the differential diagnosis of neuroblastoma and the other small round cell tumors. Am J Surg Pathol 1998; 22: 327-32. 